\title{
Performance and Emissions Comparison between Biomethane and Natural Gas Fuel in Passenger Vehicles: results of the second testing campaign
}

\author{
Fabio Cignini ${ }^{1, *}$, Antonino Genovese ${ }^{1}$, Fernando Ortenzi $^{1}$, Stefano Valentini $^{2}$, and \\ Alberto Caprioli ${ }^{3}$ \\ ${ }^{1}$ Italian National Agency for New Technologies and Environment (ENEA), Via Anguillarese,301 - \\ 00123 Rome, Italy \\ ${ }^{2}$ Attractiveness Research Territory of Emilia-Romagna region (ART-ER), Via Gobetti, 101 - 40129 \\ Bologna, Italy \\ ${ }^{3}$ IREN S.P.A., Via Nubi di Magellano, 30 - 42123 Reggio Emilia (Italy)
}

\begin{abstract}
The present paper illustrates the results of the second set of measurements carried out in the BiomethER project (EU-LIFE). BiomethER aimed to design and build two innovative bio-methane production plants, located in the Emilia Romagna region (Italy), so it aims to demonstrate that bio-methane could replace traditional methane in several applications. One of these applications is road transport where bio-methane can fuel a compressed natural gas $(\mathrm{CNG})$ vehicle. So, three passenger cars have been tested with two gases: conventional natural gas and bio-methane coming from a BiomethER plant. For each vehicle have been measured the emissions and performances on the chassis dynamometer, while an inspection of combustion chambers of the engines was carried out to evaluate their wear condition. This campaign confirms results achieved in the first one, there are no appreciable deviations for fuel consumption and $\mathrm{CO} 2$ emissions between the two fuels, acceleration and maximum power were almost the same for the three vehicles tested. Indeed, the vehicle fuelled by methane has significant carbon deposits on the piston crown while the bio-methane fuelled do not have the same.
\end{abstract}

\section{Introduction}

In later years, the European Union (EU) launched several initiatives to contrast climate change, and some were addressed to decrease the $\mathrm{CO} 2$ emissions caused by the transport sector (almost a quarter of total $\mathrm{CO} 2$ emissions). Within the transport sector, road transport is the biggest emitting source accounting for almost three-quarters of GHG emissions.

An EU strategy described within the Directive 2014/94 (DAFI) established a set of measures for the deployment of alternative fuels infrastructure to promote the development

\footnotetext{
* Corresponding author: fabio.cignini@enea.it
} 
of a large refuelling network including compressed and liquefied natural gas (CNG and LNG), hydrogen and electric energy.

The Renewable Energy Directive (RED) 2009/28 [1] settled national targets for the share of energy from renewable sources in transport in 2020 and established sustainability criteria for biofuels. Directive 2009/30 on Fuel Quality Directive (FQD) [2] sets a target for life cycles GHGs emissions reduction and defines the criteria of sustainability for biofuels inherent the GHG reduction, raw material, land use, and biodiversity protection. Finally, Directive 2018/2001 on the promotion of the use of energy from renewable sources (wellknown as RED II) imposed a share of $14 \%$ of renewable energy for the transport sector with a sub-target for advanced biofuels of $3.5 \%$ in 2030.

Accordingly, to Eurostat statistics (updated up to 2018 [3] and [4]), all 2020 targets have been widely achieved and let hope the green revolution could happen. So, the EU raised the bar with $40 \%$ of GHG reduction and $27 \%$ of renewable energy by 2030 [5], with a potential reduction of $80-95 \%$ of GHG and $55-75 \%$ of gross final energy consumption from renewable sources by 2050 [6].

A role in these big challenges can be taken from bio-methane [7]. Biomethane is produced from biogas after a cleaning and upgrading process. There are two primary production pathways for biogas: landfill and anaerobic digestion of biodegradable material. Later, biogas is cleaned from impurities (i.e. ammonia, sulphur, and hydrogen components) and upgraded to biomethane removing $\mathrm{CO} 2$.

The present paper describes the second testing campaign (of the three foreseen) during the project BiomethER [8], while the first paper [9] describes the testing methodology, measurement systems, the vehicle nominal specifications, the results of the first testing campaign and the equivalent carbon dioxide emission from well to tank and from tank to wheel. The comparison highlights that biomethane cycle life outputs $79 \%$ less GHG than traditional methane in the whole cycle life $(21 \mathrm{gCO} 2 \mathrm{eq} / \mathrm{km}$ of biomethane against 102 $\mathrm{gCO} 2 \mathrm{eq} / \mathrm{km}$ of methane). Such difference is due to less emission in the well to tank path of bio-methane, so, its utilization instead of fossil methane (or even other fossil fuels) can be a powerful way to reduce transport GHG emissions.

BiomethER Project, co-founded by EU as part of LIFE programme, aimed to design and build two innovative bio-methane production plants in the Emilia Romagna region (Italy), based on sewage sludge fermentation and landfill waste treatment (by separating the organic part of urban garbage) respectively. Specifically, the biogas derived from the sewage sludge plant is filtered and upgraded up to biomethane available for transportation. To replace the fossil methane with bio-methane in a natural gas vehicle (NGV), a comparison was performed to evaluate the energy and environmental performances of three identical vehicles powered by those two fuels.

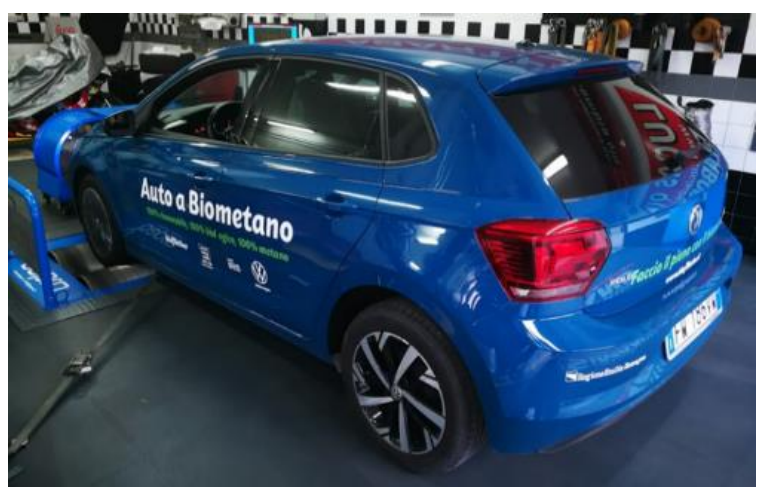

Fig. 1. One of the NGVs tested in the chassis dynamometer 
Main exhaust gas emissions, carbon dioxide (CO2), carbon monoxide (CO), nitrogen oxide (NOx) and hydrocarbons (HC), were collected by a Portable Emissions Measurement System (PEMS).

Being interesting to evaluate a trend in emissions, fuel consumption and dynamic performances a various grade of engine wear the testing campaign will be repeated when vehicles will have reach at least $30000 \mathrm{~km}$.

This paper reports the results of the second testing campaign, it is organized into four paragraphs: 2 Testing Campaign Description, 3 Results of Testing Campaign, 4 Comparison between the two campaigns and conclusions.

\section{Testing campaign description}

The target of this experimental campaign is to make a comparison of the environmental and energy performance of NGV passenger cars powered with natural gas and biomethane. Cars under testing were three passenger cars equipped with a CNG engine complying with EURO 6 standard and belonging to the B segment. Each car has a dual-fuel engine, methane (or biomethane) and gasoline.

The test methodology was defined within the project BiomethER [9] and described in the first paper of the series. Thus, these tests starting when all cars had at least 15000 kilometres covered.

Tests concern pollutant emissions and fuel consumption at dynamic roller bench on WLTC driving cycle [10] and, accelerations and maximum power measuring on the chassis dynamometer, conducted mainly at ENEA Casaccia research centre (Fig. 1) in October 2020.

A car was fuelled with standard natural gas, available at the refuelling station near the ENEA Casaccia test facility (Rome), while, the other two were powered with biomethane coming from Roncocesi (RE) biomethane production plant. During these tests, the methanepowered car run out of primary fuel (methane) and it remained with gasoline, so, it was taken the opportunity for evaluating emissions also with this fuel.

The measurement concerns fuel consumption, emissions, and dynamic performances. All of them have been collected during the following tests on the dynamometer chassis: Driving cycle, Maximum acceleration, Maximum power.

Moreover, this testing campaign foresees an inspection of the combustion chambers of the engines. Such observation aims to demonstrate if different fuels cause different wearing to the engine parts and different deposits of unburned oil and mixture.

\section{Results of testing campaign}

This chapter concerns the results of the testing campaign, it is divided into three paragraphs: emissions, performance, and inspection of the combustion chambers.

\subsection{Emissions}

Fig. 2 shows the fuel consumption and the carbon dioxide emissions for the three vehicles tested, where vehicle number 3 is the one powered by traditional methane. The three vehicles consume between 30 and $31 \mathrm{~g} / \mathrm{km}$ of fuel. The carbon dioxide emissions are between 79 and $87 \mathrm{~g} / \mathrm{km}$, they comply with the next EU regulations that prescribe $95 \mathrm{~g} / \mathrm{km}$ as limit by January the 1 st of 2020, then postponed to January 1st of 2021 [1], while the gasoline-powered vehicle reaches $107 \mathrm{~g} / \mathrm{km}$. 


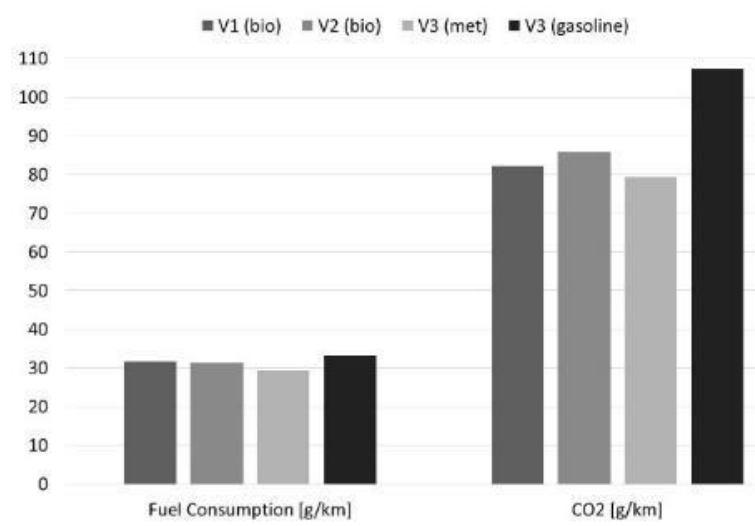

Fig. 2. Comparison of fuel consumption and $\mathrm{CO} 2$ emissions during a WLTC driving cycle.

Fig. 3 confirms that vehicles tested have all emissions under the regulatory limits independently by fuel, they are indicated in the same figure with dotted lines $(1 \mathrm{~g} / \mathrm{km}$ of CO, $0.06 \mathrm{~g} / \mathrm{km}$ of NOx, and $0.1 \mathrm{~g} / \mathrm{km}$ of $\mathrm{HC}$ ). Hence, both biomethane powered vehicles (V1 and V2) emits 33\% NOx lesser than the traditional methane, while $\mathrm{HC}$ and $\mathrm{CO}$ have not enough differences. The gasoline-powered vehicle has different emissions due to different fuels, so, it emits about $30 \%$ more $\mathrm{HC}, 20 \%$ less $\mathrm{CO}$ and between 30 to $50 \%$ less NOx.

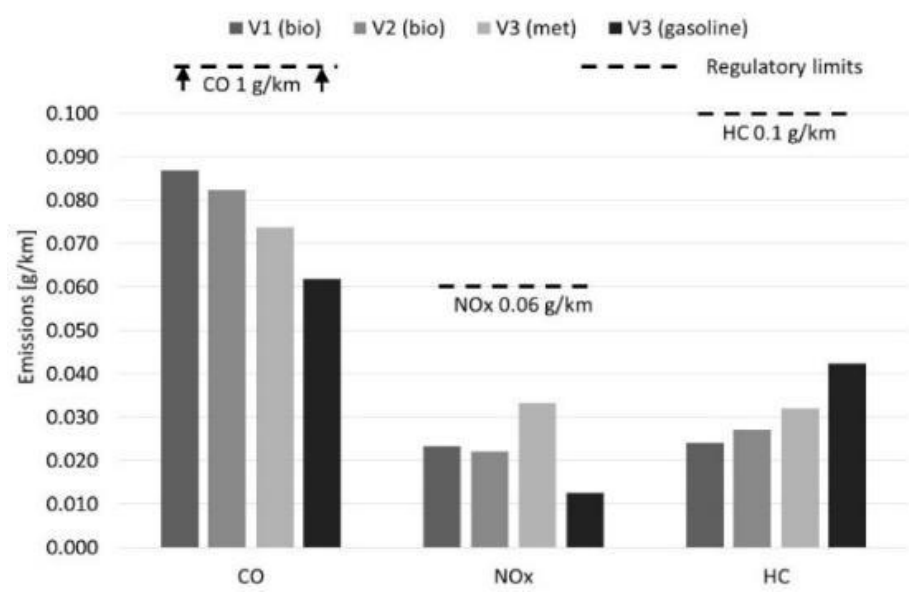

Fig. 3. Pollutants measurements during a WLTC driving cycle.

\subsection{Performance}

Table 1 summarizes results achieved during the WLTC driving cycles seen in Fig. 2 and Fig. 3.

Table 1. Results of measurements during WLTC driving cycles.

\begin{tabular}{|c|c|c|c|c|c|}
\hline Distance & $\begin{array}{c}\text { Fuel } \\
\text { consumption }\end{array}$ & CO2 & CO & NOx & HC \\
\hline Vehicle & $\mathrm{g} / \mathrm{km}$ & $\mathrm{g} / \mathrm{km}$ & $\mathrm{g} / \mathrm{km}$ & $\mathrm{g} / \mathrm{km}$ & $\mathrm{g} / \mathrm{km}$ \\
\hline V1 (Bio) & 31.7 & 82.3 & 0.087 & 0.023 & 0.024 \\
\hline V2 (Bio) & 31.2 & 85.9 & 0.082 & 0.022 & 0.027 \\
\hline V3 (Met) & 29.3 & 79.3 & 0.074 & 0.033 & 0.032 \\
\hline V3 (Gasoline) & 33.1 & 107.3 & 0.062 & 0.013 & 0.042 \\
\hline
\end{tabular}


Table 2 summarizes the results of acceleration tests. Each test has been repeated several times to improve driver skills (shifting timing and vehicle behaviour). So, Table 2 shows the better results achieved, represented by the lowest time for each test. The V2 powered by biomethane run out of fuel and can not complete the acceleration tests.

Table 2. Results of acceleration tests in seconds.

\begin{tabular}{|c|c|c|}
\hline Vehicle & $\mathbf{4 0 - 1 1 0 ~} \mathbf{~ k m} / \mathbf{h}$ & $\mathbf{0 - 1 0 0} \mathbf{~ k m} / \mathbf{h}$ \\
\hline V1 (Biomethane) & 34.00 & 17.90 \\
\hline V2 (Biomethane) & n.a. & n.a. \\
\hline V3 (Methane) & 34.00 & 18.37 \\
\hline V3 (Gasoline) & 27.10 & 17.10 \\
\hline
\end{tabular}

Fig. 4 shows the results of maximum power tests, each vehicle repeats two times the test. The maximum power is greater than or equal to the vehicle manufacturer's declaration $(67 \mathrm{~kW}$ ), for $\mathrm{V} 1$ and $\mathrm{V} 2$ (the biomethane vehicles) are between 67 and $72 \mathrm{~kW}$, and the torque is between 167 and $181 \mathrm{Nm}$. Thus, the power of V3 is about $75 \mathrm{~kW}$ and the torque is between 181 and $184 \mathrm{Nm}$. The results show power and torque losses up to $7 \%$ by biomethane vehicles in comparison with traditional methane. Such differences belong to sensors tolerance fields and are not directly connected to the fuels, especially because the two biomethane vehicles have a slight difference in performance.

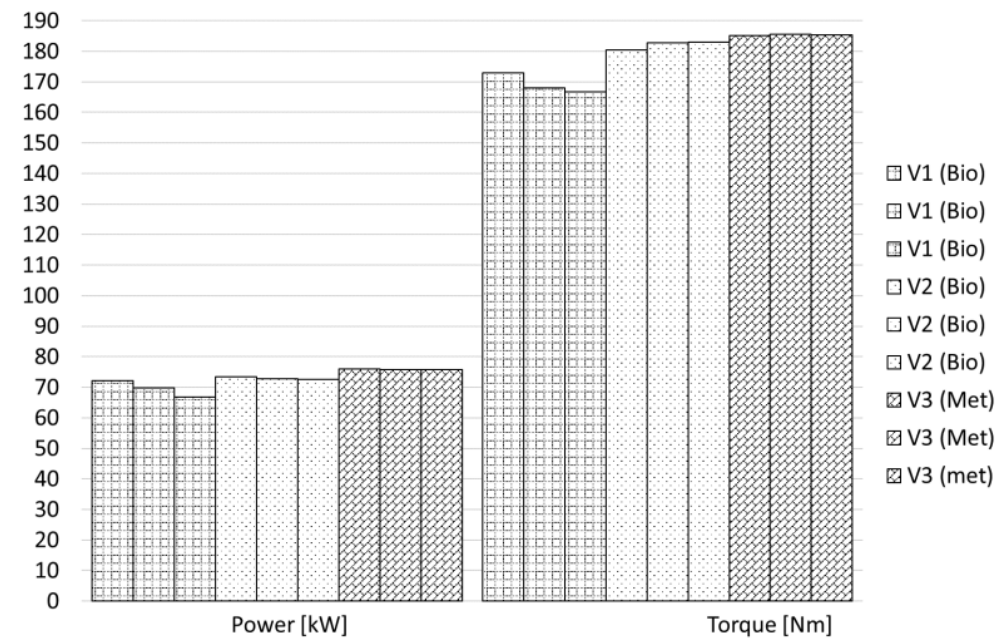

Fig. 4. Power and Torque comparison.

\subsection{Combustion chamber inspection}

This section concerns the results of the inspection carried out into the engine combustion chambers. An endoscope inserted through the hole plug allowing to examine visually the chambers of each cylinder (three for each engine for each vehicle). It has given images of the piston crown, in the following only the significant ones have been reported for each vehicle.

The piston crowns of V1 and V2 have no sign of carbon deposit. They show distinctly the QR-code and other manufacturer marks (Fig. 5 and Fig. 6). Thus, V3 shows consistent carbon deposits especially close to its edges as shown in Fig. 7, in this part of the crown the piston has a specific shaping to improve the swirl and tumble of the fuel-air mixture.

Such an amount of carbon deposits may depend on bad combustion settings or the impurities of the fuel. The first possibility is excluded, the engine status provided by ECU is 
perfectly working and there are noticed no errors, so these deposits could represent chemical components partially burned not expelled with the exhaust gases.

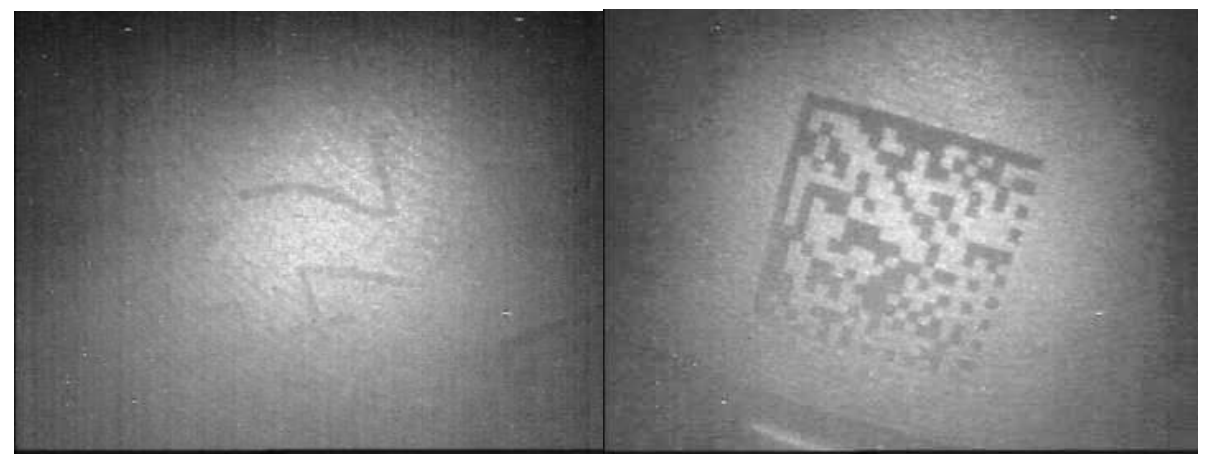

Fig. 5. V1 (bio), piston crown

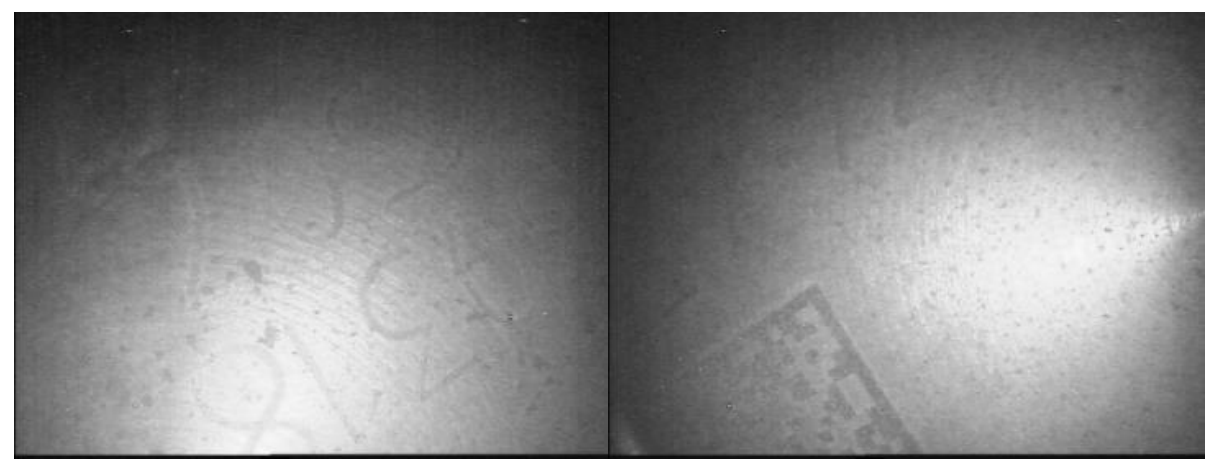

Fig. 6. V2 (bio), piston crown

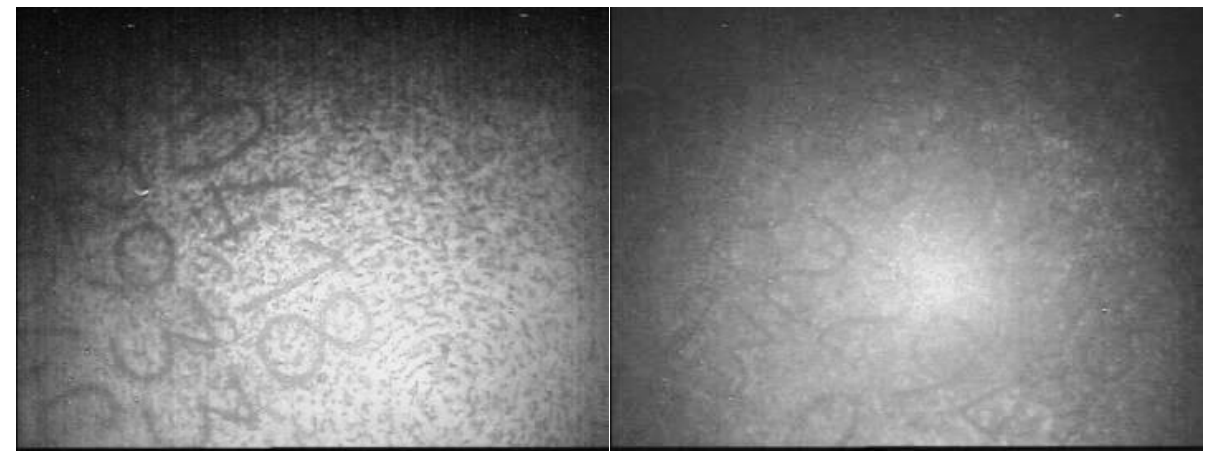

Fig. 7. V3 (met), piston crown 


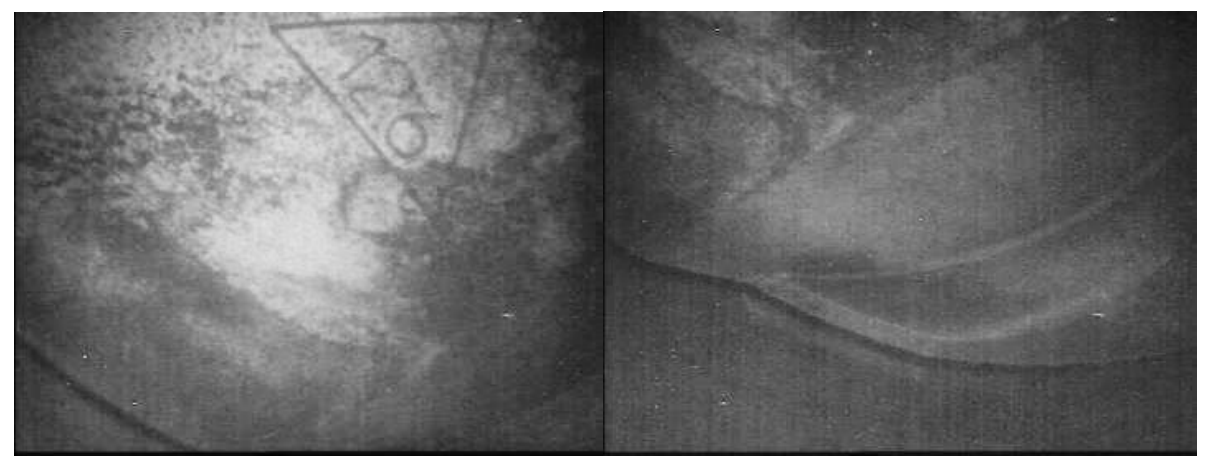

Fig. 8. V3 (met), detail of carbon deposits on the piston crown

\section{Comparison between the two campaigns and conclusions}

The present paper describes an experimental campaign of project BiomethER, where a biomethane fuel (renewable) replaces the traditional (non-renewable) methane in a natural gas vehicle (NGV). This is the second of three campaigns within the project, vehicles tested have less than $15000 \mathrm{~km}$ each. The last campaign is foreseen when the vehicle odometers will reach $30000 \mathrm{~km}$.

Three vehicles dual-fuel vehicles (methane and gasoline) have been tested by measuring fuel consumption, emissions, and dynamic performances. Two vehicles are powered by biomethane and the other one by traditional methane, moreover, this methane vehicle has been tested also when it runs out of methane fuel and it uses gasoline.

The methodology of testing and the results of the first testing campaign has been described in the previous paper.

The evaluation of the equivalent carbon dioxide emission per kilometre from well to tank and from tank to wheel, described in the first paper highlights that biomethane cycle life from well to wheel outputs $79 \%$ less GHG than traditional methane $(21 \mathrm{gCO} 2 \mathrm{eq} / \mathrm{km}$ of biomethane against $102 \mathrm{gCO} 2 \mathrm{eq} / \mathrm{km}$ of methane). Such difference is due to less emission in the well to tank path.

The tests have been conducted at the research centre ENEA by using a chassis dynamometer, a PEMS and an OBD diagnostic measurement system.

Results of emissions measurements are:

- Fuel consumption and Carbon dioxide are equal for all vehicles; they need an equal amount of gas to fulfil the WLTC driving cycles, between 31.7 and $31.2 \mathrm{~g} / \mathrm{km}$ for Biomethane vehicles, $29.3 \mathrm{~g} / \mathrm{km}$ for the methane one and 33.1 for the gasoline.

- The amount of CO2 is just under $95 \mathrm{~g} / \mathrm{km}$ (near $86 \mathrm{~g} / \mathrm{km}$ for biomethane, $79 \mathrm{~g} / \mathrm{km}$ for methane), so, it complies with the future EU limits by January 2021.

- The CO and HC pollutant emissions are not affected by fuel, they are about CO $0.08 \mathrm{~g} / \mathrm{km}$ and $\mathrm{HC} 0.03 \mathrm{~g} / \mathrm{km}$.

- The biomethane vehicles emit 33\% less NOx than the other powered by methane, 0.02 and $0.03 \mathrm{~g} / \mathrm{km}$ respectively.

- All vehicles emit pollutants under regulatory limits as manufacturer's declaration.

Dynamic performance comparison shows:

- Time of acceleration from 0 to $100 \mathrm{~km} / \mathrm{h}$ and from 40 to $100 \mathrm{~km} / \mathrm{h}$ are not affected by fuel. 
- All vehicles have a maximum power greater than or equal to $67 \mathrm{~kW}$ (as declared by the manufacturer).

- The torque varies between three vehicles with a maximum value of $10 \%$ from the smallest to the largest, equal to $18 \mathrm{Nm}$ in comparison with $183 \mathrm{Nm}$ of maximum torque for V3)

- The small differences just explained can be attributed to external variables that are not be evaluated, e.g. sensors tolerances or environmental temperature (some tests were done in the morning and some others in the afternoon).

Table 3 reports the comparison of the emissions measuring between the first and second testing campaigns, and, Table 4 reports the comparison of dynamic performances.

Table 3 Comparison of the emissions between first and second campaign

\begin{tabular}{|c|c|c|c|c|c|c|c|c|c|c|}
\hline \multirow{3}{*}{ Vehicle } & \multicolumn{2}{|c|}{$\begin{array}{c}\text { Fuel } \\
\text { consumption }\end{array}$} & \multicolumn{2}{|c|}{$\mathrm{CO} 2$} & \multicolumn{2}{|c|}{$\mathrm{CO}$} & \multicolumn{2}{|c|}{ NOx } & \multicolumn{2}{|c|}{ HC } \\
\hline & & $\mathrm{km}$ & $\mathrm{g} / \mathrm{I}$ & & $\mathrm{g} / \mathrm{l}$ & $\mathrm{sm}$ & $\mathrm{g} / \mathrm{k}$ & $\mathrm{km}$ & & $\mathrm{km}$ \\
\hline & $1000 \mathrm{~km}$ & $15000 \mathrm{~km}$ & $1000 \mathrm{~km}$ & $15000 \mathrm{~km}$ & $1000 \mathrm{~km}$ & $15000 \mathrm{~km}$ & $1000 \mathrm{~km}$ & $15000 \mathrm{~km}$ & $1000 \mathrm{~km}$ & $15000 \mathrm{~km}$ \\
\hline V1 (Bio) & 31.3 & 31.7 & 84.3 & 82.3 & 0.065 & 0.087 & 0.020 & 0.023 & 0.052 & 0.024 \\
\hline V2 (Bio) & 30.0 & 31.2 & 79.9 & 85.9 & 0.067 & 0.082 & 0.018 & 0.022 & 0.038 & 0.027 \\
\hline V3 (Met) & 30.1 & 29.3 & 82.2 & 79.3 & 0.068 & 0.074 & 0.032 & 0.033 & 0.046 & 0.032 \\
\hline V3 (Gasoline) & n.a. & 33.1 & n.a. & 107.3 & n.a. & 0.062 & n.a. & 0.013 & n.a. & 0.042 \\
\hline
\end{tabular}

Table 4 Comparison of dynamic performances

\begin{tabular}{|c|c|c|c|c|}
\hline \multirow{2}{*}{ Vehicle } & \multicolumn{2}{|c|}{$\mathbf{4 0 - 1 1 0 ~} \mathbf{~ k m} / \mathbf{h}$} & \multicolumn{2}{c|}{$\mathbf{0 - 1 0 0} \mathbf{~ k m} / \mathbf{h}$} \\
\cline { 2 - 5 } & $1000 \mathrm{~km}$ & $15000 \mathrm{~km}$ & $1000 \mathrm{~km}$ & $15000 \mathrm{~km}$ \\
\hline V1 (Biomethane) & 23.7 & 34.0 & 12.4 & 17.9 \\
\hline V2 (Biomethane) & 23.8 & n.a. & 13.7 & n.a. \\
\hline V3 (Methane) & 23.4 & 34.0 & 13.0 & 18.4 \\
\hline V3 (Gasoline) & n.a. & 27.1 & n.a. & 17.1 \\
\hline
\end{tabular}

These results highlight a few aspects:

- Fuel consumption remains the same as the first campaign (between 29 and $32 \mathrm{~g} / \mathrm{km}$ ), as the carbon dioxide, with a slight reduction in the second campaign for the methane-powered vehicle (V3).

- The CO pollutant emissions are not affected by fuel in the first campaign, while in the second there is a slight rise for the biomethane ones.

- The biomethane vehicles emit about 30\% less NOx than the ones powered by methane, for both campaigns.

- The HC emissions decrease in the second campaign by $50 \%$ for the biomethane and by $30 \%$ for the methane, while in the first campaign are the same for both fuels.

- All vehicles emit pollutants under regulatory limits as manufacturer's declaration.

Dynamic performance comparison shows:

- Time of acceleration from 0 to $100 \mathrm{~km} / \mathrm{h}$ and from 40 to $100 \mathrm{~km} / \mathrm{h}$ are not affected by fuel in both campaigns.

- All vehicles in the second campaign have a little loss in the dynamic performances, with an increase of $45 \%$ for the time to accelerate from $40 \mathrm{~km} / \mathrm{h}$ to $100 \mathrm{~km} / \mathrm{h}$ and about $30 \%$ for $0-100 \mathrm{~km} / \mathrm{h}$.

The small differences just explained can be attributed to external variables that are not be evaluated, e.g. sensors tolerances or environmental temperature (some tests were done in the morning and some others in the afternoon), or even a small variation in fuel composition. 
The next testing campaign will emphasize better the variation of performance or emission seen between first and second.

Project BiomethER "Biomethane Emilia-Romagna regional system" was co-financed by the EU LIFE program and the Emilia-Romagna Region LIFE12 ENV/IT/308. We would like to also thank the colleagues of project partners IREN Smart Solutions, Attractiveness Research Territory of EmiliaRomagna region (ART-ER), and Volkswagen Group Italia S.p.A. (VGI) for their comments that greatly improved the manuscript.

\section{References}

[1] Official Journal of the European Union, "DIRECTIVE 2009/28/EC OF THE EUROPEAN PARLIAMENT AND OF THE COUNCIL," 23 April 2009. [Online]. Available: http://www.nezeh.eu/assets/media/fckuploads/file/Legislation/RED_23April2009.pdf. [Accessed 2020].

[2] Official Journal of the European Union, "DIRECTIVE 2009/30/EC OF THE EUROPEAN PARLIAMENT AND OF THE COUNCIL," 23 April 2009. [Online]. Available: https://eurlex.europa.eu/LexUriServ/LexUriServ.do?uri=OJ:L:2009:140:0088:0113:EN:PDF. [Accessed January 2020].

[3] Eurostat, "ENERGY FROM RENEWABLE SOURCES," [Online]. Available: https://ec.europa.eu/eurostat/web/energy/data/shares. [Accessed 28 January 2020].

[4] Eurostat, "Energy, transport and environment indicators," 2018. [Online]. Available: https://ec.europa.eu/eurostat/en/web/products-statistical-books/-/KS-DK-18-001. [Accessed 15 February 2021].

[5] European Commission, "A policy framework for climate and energy in the period from 2020 to 2030," 22 January 2014. [Online]. Available: https://eur-lex.europa.eu/legalcontent/EN/TXT/?uri=COM\%3A2014\%3A15\%3AFIN. [Accessed January 2020].

[6] European Commission, "A Roadmap for moving to a competitive low carbon economy in 2050," 8 March 2011. [Online]. Available: http://www.europarl.europa.eu/meetdocs/2009_2014/documents/com/com_com(2011)0112_/com_co m(2011)0112_en.pdf. [Accessed January 2020].

[7] R. E., D. M. and H. Vervaeren, "Techniques for transformation of biogas to biomethane," Biomass and bioenergy, vol. 35, pp. 1633-1645, 2011.

[8] BiomethER project, "Chi siamo," 2012. [Online]. Available: http://www.biomether.it/p/chisiamo.html. [Accessed January 2020].

[9] F. Cignini, A. Caprioli, A. Genovese, F. Ortenzi and S. Valentini, "Performance and Emissions Comparison between Biomethane and Natural Gas Fuel in Passenger Vehicles," in 75th National ATI Congress - \#7 Clean Energy for all (ATI 2020), Rome, 2020.

[10] M. Tutuianu, A. Marotta, H. Steven, E. Ericsson, T. Haniu, N. Ichikawa and H. Ishii, "Development of a World-wide Worldwide harmonized Light-duty driving Test Cycle (WLTC)," 2013. 